\title{
Surfactant Chemical Composition and Biophysical Activity in Acute Respiratory Distress Syndrome
}

Timothy J. Gregory," William J. Longmore," Michael A. Moxley, Jeffrey A. Whitsett," Carol R. Reed," Alpha A. Fowler III," Leonard D. Hudson,' Richard J. Maunder,' Courtney Crim,"* and Thomas M. Hyers"**

${ }^{*}$ Medical Department, Ross Laboratories Division of Abbott Laboratories, Columbus, Ohio 43215; ${ }^{\ddagger}$ EA Doisy Department of Biochemistry and Molecular Biology, St. Louis University School of Medicine, St. Louis, Missouri 63104; 'Division of Neonatology, University of Cincinnati Medical Center, Cincinnati, Ohio 45267; "Department of Medicine, Medical College of Virginia, Richmond, Virginia 23298; 'Department of Medicine, Harborview Medical Center, Seattle, Washington 98104; and ${ }^{* *}$ Division of Pulmonology, St. Louis University Medical Center, St. Louis, Missouri 63110

\begin{abstract}
Acute Respiratory Distress Syndrome (ARDS) is characterized by lung injury and damage to the alveolar type II cells. This study sought to determine if endogenous surfactant is altered in ARDS. Bronchoalveolar lavage was performed in patients atrisk to develop ARDS (AR, $n=20$ ), with ARDS (A, $n=66$ ) and in normal subjects $(N, n=29)$. The crude surfactant pellet was analyzed for total phospholipids (PL), individual phospholipids, SP-A, SP-B, and minimum surface tension $\left(\right.$ ST $\left._{\min }\right)$. PL was decreased in both $A R$ and $A(3.48 \pm 0.61$ and $2.47 \pm 0.40$ $\mu \mathrm{mol} / \mathrm{ml}$, respectively) compared to $\mathrm{N}(7.99 \pm 0.60 \mu \mathrm{mol} / \mathrm{ml})$. Phosphatidylcholine was decreased in A $(62.64 \pm 2.20 \%$ PL) compared to $\mathrm{N}(\mathbf{7 6 . 2 7} \pm 2.05 \%$ PL). Phosphatidylglycerol was $11.58 \pm 1.21 \% \mathrm{PL}$ in $\mathrm{N}$ and was decreased to $6.48 \pm 1.43 \% \mathrm{PL}$ in A. SP-A was $123.64 \pm 20.66 \mu \mathrm{g} / \mathrm{ml}$ in $\mathrm{N}$ and was decreased to 49.28 $\pm 21.68 \mu \mathrm{g} / \mathrm{ml}$ in $\mathrm{AR}$ and to $29.88 \pm 8.49 \mu \mathrm{g} / \mathrm{ml}$ in A. SP-B was $1.28 \pm 0.33 \mu \mathrm{g} / \mathrm{ml}$ in $\mathrm{N}$ and was decreased to $0.57 \pm 0.24$ $\mu \mathrm{g} / \mathrm{ml}$ in $\mathbf{A} . \mathrm{ST}_{\min }$ was increased in $\mathbf{A R}(15.1 \pm 2.53 \mathrm{dyn} / \mathrm{cm})$ and $A(29.04 \pm 2.05 \mathrm{dyn} / \mathrm{cm})$ compared to $N(7.44 \pm 1.61 \mathrm{dyn} / \mathrm{cm})$. These data demonstrate that the chemical composition and functional activity of surfactant is altered in ARDS. Several of these alterations also occur in AR, suggesting that these abnormalities occur early in the disease process. (J. Clin. Invest. 1991. 88:1976-1981.) Key words: phospholipids • surfactantassociated proteins $\bullet$ surface activity $\bullet$ at-risk patients $\bullet$ and normal subjects
\end{abstract}

\section{Introduction}

Previous investigations suggested that abnormalities of the surfactant system occur in patients with Acute Respiratory Distress Syndrome (ARDS, ${ }^{1}$ also known as Adult Respiratory Dis-

\footnotetext{
Address reprint requests to Timothy J. Gregory, Ph.D., Medical Department, Ross Laboratories, 625 Cleveland Ave., Columbus, OH 43215. Received for publication 1 April 1991 and in revised form 22 July 1991

1. Abbreviations used in this paper: ARDS, acute respiratory distress syndrome; BAL, bronchoalveolar lavage; CSP, crude surfactant pellet; LPC, lysophosphatidylcholine; PCP, Pneumocystis carinii pneumonia; PE, phosphatidylethanolamine; PI, phosphatidylinositol; PL, phospholipid; PS, phosphatidylserine; SM, sphingomyelin.
}

J. Clin. Invest.

(C) The American Society for Clinical Investigation, Inc. 0021-9738/91/12/1976/06 \$2.00

Volume 88, December 1991, 1976-1981 tress Syndrome) (1-4). However, because of the difficulty in obtaining surfactant from these patients, the available data are incomplete. Ashbaugh et al., in their original description of ARDS, reported an increased minimum surface tension in surfactant obtained from specimens of minced lungs obtained at autopsy from ARDS patients (1). In subsequent reports, Petty and colleagues observed a lighter surfactant buoyant density (2) and increased surfactant compressibility $(2,3)$ in bronchoalveolar lavage (BAL) material obtained from the lungs of ARDS patients immediately after their death. Intriguing observations of surfactant composition and functional activity in ARDS patients were made by Hallman et al. (4), who reported a decrease in the percentages of disaturated phosphatidylcholine and phosphatidylglycerol in BAL samples obtained from ARDS patients. In addition, they observed an increase in the minimum surface tension in the surfactant lavaged from ARDS patients.

Various mechanisms may be responsible for such alterations in the surfactant system. Acute lung injury associated with ARDS results in damage to the alveolar type II cells (5) which may result in decreased and/or altered surfactant production. Mediators of the acute lung injury, such as toxic oxygen radicals (6) and proteolytic enzymes $(7,8)$, may also damage endogenous surfactant. As alveoli are flooded with plasma proteins over the early stages of ARDS, endogenous surfactant may be inactivated (9-11) or washed away (12). When surfactant production is reduced or surfactant is damaged, alveoli collapse, producing hypoxemia and the creation of hydrostatic forces that favor edema formation (13-15); thus resulting in further surfactant alterations.

The present study was designed to examine, describe, and compare the chemical composition and biophysical activity of surfactant obtained by bronchoalveolar lavage from ARDS patients, patients at risk to develop ARDS, and normal subjects. A unique feature of this study is the inclusion of a group of patients at high risk to develop ARDS; a group of patients, that with one exception, never developed ARDS.

\section{Methods}

This was a study of surfactant chemical composition and biophysical activity in three groups of subjects; normal volunteers, patients at-risk to develop ARDS, and patients with ARDS. The study was conducted at three clinical centers: The Medical College of Virginia (Richmond, VA), Harborview Medical Center (Seattle, WA), and St. Louis University Medical Center (St. Louis, MO).

The Institutional Review Board at each center had reviewed and approved the protocol for bronchoalveolar lavage in at-risk and ARDS patients. The protocol for bronchoalveolar lavage in normal subjects 
was approved by the Institutional Review Boards at the Medical College of Virginia and St. Louis University Medical Center but not at Harborview Medical Center. Therefore, no lavages from normal subjects were obtained from this center. Each subject or his/her legal guardian gave informed consent before study entry.

Bronchoalveolar lavage samples were analyzed for total protein, total phospholipid, individual phospholipids, and biophysical activity in the EA Doisy Department of Biochemistry and Molecular Biology, St. Louis University School of Medicine. Surfactant-associated protein analyses were performed in the Division of Neonatology, University of Cincinnati Medical Center.

\section{Patient selection}

Three groups of subjects were studied: patients at risk for ARDS, patients with ARDS, and normal subjects.

Patients were considered at-risk for ARDS if they had experienced at least one of the following: trauma and hypotension, multiple blood transfusions, sepsis, witnessed aspiration of gastric contents, pneumonia requiring intensive care, long bone or pelvic fractures, disseminated intravascular coagulation, pancreatitis, thermal burns, inhalation of toxic gases, or near-drowning. Criteria for entry into one of these at-risk groups were as follows:

1. Trauma and hypotension. Acute trauma which included surgical operations associated with blood loss with systemic blood pressure $<80 \mathrm{mmHg}$ systolic for longer than $2 \mathrm{~h}$ or the requirement for vasopressor agents for $>2 \mathrm{~h}$. Sepsis and cardiogenic shock were excluded.

2. Multiple blood transfusions. Infusion of $10 \mathrm{U}$ or more of packed red cells or whole blood in $24 \mathrm{~h}$.

3. Sepsis. Included patients with bacteremia and those with the physiologic concomitants of sepsis but whose blood did not grow pathogenic bacteria. These groups were known as sepsis and sepsis syndrome. (a) Sepsis. The presence of microorganisms or their toxins in blood. A positive blood culture for a recognized bacterial pathogen or a positive limulus lysate assay was required. (b) Sepsis syndrome. Fever $\left(T>39^{\circ} \mathrm{C}\right.$ ), leukocytes (WBC $>12,000$ ) or blood differential shift (> 10\% immature granulocytes) associated with a deleterious organ response of one of the following: systolic blood pressure $<100 \mathrm{mmHg}$ or vasopressor support, urine output $<30 \mathrm{ml} / \mathrm{h}$, systemic vascular resistance $<800 \mathrm{dyn} / \mathrm{cm}^{-5}$ or blood lactate levels $>2.0 \mathrm{Mm}$.

4. Aspiration of gastric contents. Witnessed aspiration of gastric contents or foodstuffs. Confirmation by suctioning of gastric material from the trachea was helpful, but not necessary.

5. Pneumonia. Fever or other appropriate prodrome with focal pulmonary infiltrate on chest roentgenogram. Diagnosis was confirmed by culture of a bacterial pathogen from the sputum or blood, or in the case of viruses, by subsequent rises of antibody titer in serum.

6. Long bone or pelvic fractures. Fracture of two or more major long bones or one long bone and a pelvic fracture.

7. Disseminated intravascular coagulation. Spontaneous or prolonged bleeding from two or more sites associated with acute evidence

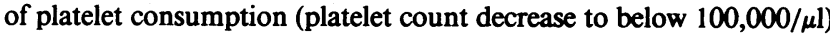
or fibrinogen degradation (FDP serum titer $>1: 40$ ).

8. Pancreatitis. Abdominal pain, nausea, and vomiting with a serum amylase $>4 \mathrm{IU} / \mathrm{ml}$ with no other explanation for these findings.

9. Thermal burns. Second or third degree burns involving $>20 \%$ body surface area.

10. Inhalation of toxic gases. A history of inhalation within $6 \mathrm{~h}$ of smoke or other toxic gas.

11. Near drowning. A history of fresh-water immersion associated with respiratory arrest.

All of these at-risk patients had developed acute respiratory failure and had been intubated and placed on mechanical ventilation. They had not, however, developed ARDS as defined below.

Patients were considered to have ARDS if they had one of the above listed predisposing risk factors, were endotracheally intubated, and had acute respiratory failure with bilateral alveolar infiltrates, $\mathrm{a} \mathrm{PaO}_{2} / \mathrm{FiO}_{2}$ ratio $<150$ (or $<200$ in the case of PEEP administration), and pulmonary capillary wedge pressure $<18 \mathrm{mmHg}$.
Normal subjects were volunteers with no prior history of lung disease. They were not intubated or mechanically ventilated at the time of the lavage.

Patients were excluded from the study if they had disseminated cancer of the lung; chronic interstitial lung disease, chronic obstructive lung disease, cardiogenic shock, recent head trauma, stroke or subarachnoid hemorrhage. Although patients with Pneumocystis carinii pneumonia (PCP) were not specifically excluded from the study, there were no PCP patients enrolled in the study.

\section{Bronchoalveolar lavage}

Bronchoalveolar lavage was performed by fiberoptic bronchoscope through indwelling endotracheal or nasotracheal tubes. The distal end of the bronchoscope wedged into a segment of the right middle lobe, the lingula or to one of the lower lobes. Three aliquots of $50 \mathrm{ml}$ each of sterile saline were infused through the bronchoscope and withdrawn after each infusion into the injection syringe. The lavage fluid was immediately pooled and placed on ice. Any lavage fluid foam created during the procedure was included in the pooled sample.

Aliquots of the fluid were removed for cell counts, for cytomorphology by cytocentrifugation and for bacterial culture and Gram stain. The remaining lavage fluid, including the foam, was then centrifuged at $450 \mathrm{~g}$ for $10 \mathrm{~min}$ at $4^{\circ} \mathrm{C}$ to remove the cell pellet. This centrifugation was performed within $30 \mathrm{~min}$ of the lavage procedure. The supernatant of the low-speed centrifugation, as well as any residual foam, was frozen and stored at $-70^{\circ} \mathrm{C}$ until shipped to St. Louis University School of Medicine. Lavage samples were packaged on dry ice and shipped by overnight mail. Lavage samples were maintained at $-80^{\circ} \mathrm{C}$ until analyzed.

\section{Lavage analysis}

The BAL supernatant from the low-speed centrifugation was thawed, mixed, and centrifuged at $48,000 \mathrm{~g}$ for $60 \mathrm{~min}$ at $4^{\circ} \mathrm{C}$. The high-speed supernatant was decanted and the crude surfactant pellet (CSP) was resuspended in $200 \mu$ of saline containing $5 \mathrm{mM} \mathrm{CaCl}_{2}$ and analyzed for total protein, total phospholipid, individual phospholipids, surfactant-associated proteins, and biophysical activity.

Total phospholipids were extracted by the method of Bligh and Dyer (16). A trace amount of (di-1-7. ${ }^{14} \mathrm{C}$-palmitoyl)phosphatidylcholine (Amersham Corp., Arlington Heights, IL) was added to quantitate recovery. Total protein was determined on an aliquot of each sample by a modification of the method of Lowry (17) and was expressed per milliliter of resuspended CSP. Total phospholipid was quantitated by assaying organic phosphorus as described by Dittmer and Wells (18) and was expressed per milliliter of resuspended CSP. The individual phospholipids were separated according to Fine and Sprecher (19). Each phospholipid was assayed as described by directly digesting the gel, with the exception of phosphatidylcholine which was extracted from the silica. The profile for individual phospholipid composition is expressed as a percentage of the total phospholipid present on the thinlayer chromatography (TLC) plate. Disaturated phosphatidylcholine was determined on an aliquot of the extracted phosphatidylcholine according to a modification of Mason et al. (20) as described by Tsai, Cain and Josephson (21).

Samples were analyzed for SP-A content in a double-antibody ELISA. Surfactant protein A was purified from surfactant obtained by lung lavage of a patient with alveolar proteinosis $(22,23)$. Polyclonal anti-human SP-A antibodies were prepared in goats and New Zealand rabbits by repeated injection of $\sim 1 \mathrm{mg}$ purified AP-A in Freund's complete adjuvant. The antisera were specific for SP-A as assessed by immunoblot of alveolar proteinosis lavage and human amniotic fluid. The goat and rabbit anti-SP-A antisera were used as first and second antibodies in a capture ELISA as previously described (24). Each assay plate included a standard curve generated with purified human SP-A $(5-100 \mathrm{ng} / \mathrm{ml})$ and four serial dilutions of each sample.

SP-B was determined in a double antibody ELISA. Surfactant protein B was purified from bovine lung as previously described (25). The purity and concentration of the bovine SP-B standard was confirmed 
by amino acid composition utilizing reverse-phase HPLC on a PicoTag column (Waters Chromatography Division of Millipore, Milford, MA) to quantitate phenylthiocarbamyl-amino acid derivatives and by sequence analysis by Edman degradation and gas phase sequencer (2629). The homology between bovine and human SP-B is 80\% (30). Polyclonal anti-human SP-B antibodies were generated in New Zealand rabbits by repeated injection of a human-based synthetic SP-B polypeptide (AA 1-60) in Freund's complete adjuvant (31). Monoclonal anti-human SP-B antiserum was prepared from a ascitic fluid of nude mice injected intraperitoneally with mouse spleen-myeloma hybridomas selectively producing anti-human antibodies. The murine cells were isolated by dilutional cloning from mice repeatedly immunized with organic solvent extract of human cadaver lung surfactant in Freund's adjuvant. The specificity of the anti-SP-B antisera was demonstrated by immunoblot of bovine serum, whole bovine surfactant, purified bovine SP-B, and human surfactant (25). The rabbit and mouse anti-SP-B antisera were used as first and second antibodies in a capture ELISA as previously described (24). Each assay plate included a standard curve generated with purified bovine SP-B $(5-100 \mathrm{ng} / \mathrm{ml})$ and four serial dilutions of each sample.

Samples were not analyzed for SP-C. A specific anti-human SP-C antiserum could not be raised due to the extreme hydrophobicity of SP-C.

Surface tension was analyzed using a pulsating bubble surfactometer (32) with all samples adjusted to $1.5 \mathrm{mM}$ phosphorus concentration in saline containing $5 \mathrm{mM} \mathrm{CaCl}_{2}$.

\section{Statistical methods}

Categorical data such as gender and presence of risk factors were summarized by frequency counts. Continuous data such as age and $\mathrm{PaO}_{2} /$ $\mathrm{FiO}_{2}$ at study entry were summarized by means and standard errors for each group (normal, at-risk, ARDS). Crude surfactant pellet data for all variables were summarized by means, standard errors, medians for each group.

Pairwise comparisons of lavage data were made via the Wilcoxon rank sum test (33), a nonparametric analogue of the two-sample $t$ test. Significance was assessed at $\alpha=0.050$; no adjustment was made for multiple comparisons. $P$ values $<0.001$ are reported as 0.001 .

\section{Results}

116 subjects entered the study. 29 were normals, 20 were atrisk for ARDS at entry, and 67 had ARDS at entry. Most (17 of 29) of the normal subjects were female, whereas most at-risk (15 of 20) and ARDS (41 of 67) patients were male. Normals were young (mean age, 28.80) compared with at-risk and ARDS patients (mean ages 51.35 and 45.45 , respectively).

At the time of study entry, the $\mathrm{PaO}_{2} / \mathrm{FiO}_{2}$ was $252.3 \pm 24.6$ for at-risk patients and 114.0 \pm 6.0 for ARDS patients. The $\mathrm{PaO}_{2} / \mathrm{FiO}_{2}$ was not measured in normal subjects. Patient's predisposing risk factors at study entry are shown in Table I. Atrisk patients were lavaged $12 \pm 3 \mathrm{~h}$ after the identification of their predisposing risk factor(s) and study entry. They had been intubated and placed on mechanical ventilation $13 \pm 10 \mathrm{~h}$ before study entry. ARDS patients were lavaged $87 \pm 9 \mathrm{~h}$ after the diagnosis of ARDS was made and they were entered into the study. They had been intubated and placed on mechanical ventilation $37 \pm 7 \mathrm{~h}$ before study entry. In the at-risk patients, $37.4 \pm 3.2 \%$ of the lavage instillate was recovered, whereas $55.1 \pm 1.8 \%$ of the lavage instillate was recovered in the ARDS patients. In the normal subjects, $63.3 \pm 2.2 \%$ of the lavage instillate was recovered.

Descriptions of CSP lavage protein, phospholipids, and surface tension are shown in Tables II-V. Median total phospholipid and median total protein were significantly higher in nor-
Table I. Summary of Patient Predisposing Risk Factors at Study Entry

\begin{tabular}{llr}
\hline Group & \multicolumn{1}{c}{ Etiology } & Number \\
\hline At-risk & Trauma or multiple blood transfusions & 4 \\
& Sepsis & 4 \\
& Sepsis syndrome & 3 \\
& Aspiration & 3 \\
& Other etiologies & 2 \\
& Multiple etiologies & 4 \\
& Total & 20 \\
ARDS & Trauma or multiple blood transfusions & 15 \\
& Sepsis & 11 \\
& Sepsis syndrome & 0 \\
& Aspiration & 6 \\
& Other etiologies & 4 \\
& Multiple etiologies & 31 \\
& Total & 67
\end{tabular}

Other etiologies include: pneumonia, pelvic Fx, DIC, pancreatitis, IV drug abuse, burns- $40 \%$, smoke inhalation, near drowning, aspirin overdose, surgery, pulmonary contusion, drug overdose, gastrointestinal bleeding, and unknown. Multiple etiologies include combinations of specified etiologies and/or other etiologies.

mal subjects than in either of the other groups; medians in at-risk and ARDS groups were not different from each other (Table II). Median phospholipid/protein was significantly lower in the ARDS group than in either of the other groups (Table II).

The individual phospholipid composition is expressed as the percentage of total phospholipids recovered from the TLC plate. Phosphatidylcholine (PC) was lower in ARDS patients than in normals or at-risk patients (Table III). Disaturated phosphatidylcholine (DSPC) was not significantly different between the three groups (Table III). Phosphatidylglycerol (PG) was greater in normals than in ARDS patients (Table III). Phosphatidylinositol (PI) was significantly higher in the ARDS group than in either of the other groups (Table III). Phosphatidylserine (PS) was not significantly different between the three groups (Table III). Phosphatidylethanolamine (PE) was significantly lower in the normal subjects than in either of the other groups; the at-risk and ARDS groups were not different from each other (Table III). Lysophosphatidylcholine (LPC) was significantly lower in the normal subjects than in either of the other groups; the at-risk and ARDS groups were not different from each other (Table III). Sphingomyelin (SM) was significantly higher in the ARDS group than in either of the other groups (Table III).

Surfactant-associated protein A (SP-A) in the CSP was significantly higher in normals than in the other groups (Table IV). CSP surfactant-associated protein B (SP-B) was significantly lower in ARDS patients than in normals or at-risk patients (Table IV).

Minimum surface tension $\left(S T_{\min }\right.$ ) by pulsating bubble surfactometer was greater in at-risk patients than in normals and greater in ARDS patients than in those at-risk (Table V). Surface tension maxima greater than 54 were not recorded consistently in the study. In some instances, they were truncated to 54 ; in other instances, actual values were recorded. A surface tension maximum $\left(S T_{\max }\right)$ of 54 was imposed a posteriori for 
Table II. Crude Surfactant Pellet Phospholipid and Protein in Normal Subjects, At-risk Patients, and ARDS Patients

\begin{tabular}{llccc}
\hline & & $\begin{array}{c}\text { Normal } \\
\text { subjects }\end{array}$ & $\begin{array}{c}\text { At-risk } \\
\text { patients* }\end{array}$ & $\begin{array}{c}\text { ARDS } \\
\text { patients* }\end{array}$ \\
\hline $\begin{array}{c}\text { Total phospholipid (PL) } \\
(\mu \mathrm{mol} / \mathrm{ml})\end{array}$ & $n$ & & & \\
& Mean & 7.99 & 3.48 & 2.47 \\
& SEM & 0.60 & 0.84 & 0.40 \\
& Median & 7.54 & $1.62^{\ddagger}$ & $1.33^{\ddagger}$ \\
Total protein (PRO) & & & & \\
$(m g / m l)$ & $n$ & 29 & 20 & 66 \\
& Mean & 2.85 & 1.94 & 1.82 \\
& SEM & 0.32 & 0.81 & 0.26 \\
Phospholipid/protein & Median & 2.40 & $1.01^{\ddagger}$ & $0.97^{\ddagger}$ \\
$($ PL/PRO) & & & & \\
& $n$ & 29 & 20 & 66 \\
& Mean & 3.44 & 2.57 & 2.67 \\
& SEM & 0.32 & 0.41 & 0.67 \\
& Median & 3.51 & 2.05 & $1.06^{\ddagger}$ \\
& & & & \\
\hline
\end{tabular}

* Compared to normal subjects.

${ }^{\ddagger} P=0.001$

statistical analysis. $S T_{\max }$ was greater in at-risk patients than in normals and greater in ARDS patients than in at-risk patients (Table V).

\section{Discussion}

This study confirmed that ARDS is associated with abnormalities in the pulmonary surfactant system as is demonstrated by changes in both the chemical composition and the biophysical activity of the isolated surfactant.

The total lavagable surfactant pool was decreased in ARDS patients as demonstrated by the decreased concentration of total phospholipid. This deceased surfactant pool may be the result of alveolar type II cell injury and altered synthesis of surfactant. In addition, mediators of the acute lung injury that occurs in ARDS may have damaged surfactant after it is secreted into the alveolar space.

The profile of the individual phospholipids in ARDS patients demonstrates decreased levels of PC and PG and increased levels of PI, PE, LPC, and SM. These changes in the lavagable surfactant phospholipid composition may be related to altered surfactant reuptake and synthesis by injured alveolar type II cells. In addition, these results may be due to contamination from membrane phospholipids such as PI, PS, PE, LPC, and SM, resulting from damaged alveolar type II cells, other airway lining cells, inflammatory cells, or other lung tissue.

The lavagable concentrations of the SP-A and SP-B were decreased. The decreased levels of surfactant-associated proteins are likely to be due to altered synthesis of surfactant and/ or damage to the surfactant once it is secreted into the alveolar space.

One interesting finding of this study was the decreased total protein in the CSPs obtained from both the at-risk and ARDS patients. Typically, one would expect the total protein concentration to increase due to an increased concentration of plasma proteins in the alveoli resulting from the permeability defect observed in these patients. One possible explanation for this finding is that the purification process utilized for sample analy- sis might have removed these proteins. Another possible explanation is that the plasma proteins which have leaked into the alveolar space become condensed, along with cellular debris, into the dense, eosinophilic hyaline membranes which are observed during the exudative phase of ARDS (34). These hyaline membranes and the plasma proteins within them may not be recoverable by BAL.

The biophysical activity of surfactant lavaged from ARDS patients was decreased as demonstrated by the increase in minimum surface tension of these samples. This decreased activity may be due to altered chemical composition or may be the result of inhibitors of surfactant function. It is not possible with the present experimental design to distinguish between these. However, if our purification process is responsible for the de-

Table III. Crude Surfactant Pellet Phospholipid Chemical Composition in Normal Subjects, At-risk Patients, and ARDS Patients

\begin{tabular}{|c|c|c|c|c|}
\hline & & $\begin{array}{l}\text { Normal } \\
\text { subjects }\end{array}$ & $\begin{array}{c}\text { At-risk } \\
\text { patients* }\end{array}$ & patients \\
\hline \multicolumn{5}{|l|}{ Phospholipids (\% PL) } \\
\hline \multirow{4}{*}{ Phosphatidylcholine (PC) } & $n$ & 29 & 11 & 50 \\
\hline & Mean & 76.27 & 73.32 & 62.64 \\
\hline & SEM & 2.05 & 4.51 & 2.20 \\
\hline & Median & 76.20 & 78.00 & $63.1^{\ddagger}$ \\
\hline \multirow{4}{*}{$\begin{array}{l}\text { Disaturated phosphatidylcholine } \\
\text { (DPPC) }\end{array}$} & $n$ & 13 & 7 & 21 \\
\hline & Mean & 46.98 & 53.89 & 42.77 \\
\hline & SEM & 2.81 & 4.37 & 4.25 \\
\hline & Median & 50.60 & 56.50 & 44.00 \\
\hline \multirow[t]{4}{*}{ Phosphatidylglycerol (PG) } & $n$ & 29 & 10 & 44 \\
\hline & Mean & 11.58 & 7.26 & 6.48 \\
\hline & SEM & 1.21 & 1.53 & 1.43 \\
\hline & Median & 10.70 & 8.90 & $4.00^{\ddagger}$ \\
\hline \multirow[t]{4}{*}{ Phosphatidylinositol (PI) } & $n$ & 16 & 8 & 34 \\
\hline & Mean & 3.88 & 4.71 & 6.94 \\
\hline & SEM & 0.75 & 2.39 & 0.73 \\
\hline & Median & 2.69 & 2.15 & $6.80^{\S}$ \\
\hline \multirow[t]{4}{*}{ Phosphatidylserine (PS) } & $n$ & 16 & 8 & 34 \\
\hline & Mean & 1.80 & 3.75 & 2.84 \\
\hline & SEM & 0.27 & 1.81 & 0.53 \\
\hline & Median & 1.80 & 1.45 & 2.25 \\
\hline \multicolumn{5}{|l|}{ Phosphatidylethanolamine } \\
\hline & $n$ & 29 & 10 & 44 \\
\hline & Mean & 3.32 & 4.90 & 5.86 \\
\hline & SEM & 0.46 & 1.60 & 0.71 \\
\hline & Median & 2.83 & 3.00 & $5.75^{\prime \prime}$ \\
\hline \multicolumn{5}{|l|}{ Lysophosphatidylcholine } \\
\hline \multirow[t]{4}{*}{ (LPC) } & $n$ & 29 & 10 & 43 \\
\hline & Mean & 0.16 & 1.34 & 2.32 \\
\hline & SEM & 0.09 & 0.66 & 0.94 \\
\hline & Median & 0.00 & $0.30^{\prime \prime}$ & $0.00^{\prime \prime}$ \\
\hline \multirow[t]{4}{*}{ Sphingomyelin (SM) } & $n$ & 28 & 10 & 43 \\
\hline & Mean & 1.45 & 1.56 & 5.45 \\
\hline & SEM & 0.36 & 0.90 & 0.81 \\
\hline & Median & 1.15 & 0.60 & $4.00^{\ddagger}$ \\
\hline
\end{tabular}

* Compared to normal subjects.

${ }^{\ddagger} P=0.001$

${ }^{5} P<0.01$.

" $P<0.05$. 
creased total protein concentrations observed, as mentioned above, then it is not likely that plasma proteins, such as albumin and fibrinogen, are responsible for the inhibition of surfactant activity in these samples. We cannot, however, does not rule out the presence of other inhibitors such as hydrophobic proteins nor do we minimize the importance of plasma proteins as potential inhibitors of surfactant activity.

Pison and his colleagues have reported two recent studies of surfactant composition and functional activity in ARDS patients $(35,36)$. In their first study, they examined BAL samples from trauma patients with respiratory failure (35). Unlike our study, they found that total lavage phospholipid content was not different than that of healthy control subjects. However, they did observe a decrease in the relative amounts of $\mathrm{PC}$ and PG and an increase in PI, PE, and SM. Minimum surface tension was not significantly elevated in the trauma patients when compared to the healthy controls which is also different from the results of our study. There was, however, a significant decrease in the hysteresis area of the surface tension diagrams obtained from the BAL of the trauma patients. In their second study, Pison et al. (36) confirmed these results in a group of trauma patients with uncomplicated courses of acute respiratory failure. They also studied a group of trauma patients whose acute respiratory failure was complicated by septicemia. In the group of septic patients, the level of PC was decreased and the level of PE was increased compared to the uncomplicated trauma patients.

The differences between the results of our study and those of Pison et al. may be due to differing patient populations. While Pison's group studied trauma patients with and without sepsis, our study was comprised of patients with many predisposing risk factors. In addition, we obtained a single lavage during the patient's clinical course while Pison et al. obtained multiple lavages during the patient's clinical course and averaged many of their findings. Certainly other explanations may also exist but future studies will be necessary to further address the differences.

The present study also demonstrated abnormalities in the lavagable surfactant of patients at risk to develop ARDS. Both the chemical composition and the biophysical activity of the surfactant were altered. The total lavagable surfactant pool was decreased as demonstrated by the decreased concentration of

Table IV. Crude Surfactant Pellet Surfactant-associated Proteins in Normal Subjects, At-risk Patients, and ARDS Patients

\begin{tabular}{llccc}
\hline & & $\begin{array}{c}\text { Normal } \\
\text { subjects }\end{array}$ & $\begin{array}{c}\text { At-risk } \\
\text { patients }\end{array}$ & $\begin{array}{c}\text { ARDS } \\
\text { patients }\end{array}$ \\
\hline $\begin{array}{c}\text { Surfactant-associated proteins } \\
(\mu g / m l)\end{array}$ & & & & \\
SP-A & $n$ & 29 & 20 & 67 \\
& Mean & 123.64 & 49.28 & 29.88 \\
& SEM & 20.66 & 21.68 & 8.49 \\
SP-B & Median & 118.04 & $8.81^{\ddagger}$ & $6.18^{\ddagger}$ \\
& $n$ & 18 & 11 & 54 \\
& Mean & 1.28 & 0.89 & 0.57 \\
& SEM & 0.33 & 0.54 & 0.24 \\
& Median & 0.66 & 0.36 & $0.05^{\ddagger}$ \\
\hline
\end{tabular}

* Compared to normal subjects.

${ }^{\ddagger} P=0.001$.
Table V. Crude Surfactant Pellet Surfactant Biophysical Activity in Normal Subjects, At-risk Patients, and ARDS Patients

\begin{tabular}{llccc}
\hline & & $\begin{array}{c}\text { Normal } \\
\text { subjects }\end{array}$ & $\begin{array}{c}\text { At-risk } \\
\text { patients* }\end{array}$ & $\begin{array}{c}\text { ARDS } \\
\text { patients* }\end{array}$ \\
\hline Surface activity $($ dyn/cm $)$ & & & & \\
Minimum & $n$ & 29 & 20 & 64 \\
& Mean & 7.44 & 15.10 & 29.04 \\
& SEM & 1.61 & 2.53 & 2.05 \\
Maximum & Median & 4.10 & $16.7^{\ddagger}$ & $24.00^{\S}$ \\
& $n$ & 29 & 20 & 64 \\
& Mean & 35.76 & 44.56 & 53.03 \\
& SEM & 1.97 & 2.74 & 1.77 \\
& Median & 35.00 & $48.50^{\prime \prime}$ & $54.00^{8}$ \\
\hline
\end{tabular}

* Compared to normal subjects.

${ }^{\ddagger} P<0.05$.

${ }^{8} P=0.001$.

$\| P<0.01$.

total phospholipid. The profile of the individual phospholipids demonstrated an increased level of LPC. The lavagable concentrations of the SP-A was decreased. The biophysical activity of surfactant lavaged from at-risk patients was decreased as demonstrated by the increase in both the minimum and maximum surface tension of these samples as assessed by pulsating bubble surfactometer.

This finding is unique in this population of at-risk patients. We are aware of no other measurable variable that has been reported to be consistently abnormal in the at-risk patient. These patients are representative of a population of patients who have been admitted to the intensive care unit with acute respiratory failure. They are intubated, mechanically ventilated, and have at least one underlying predisposing risk factor. These are patients with mild lung injury and significant gas exchange abnormalities, as indicated by the observed $\mathrm{PaO}_{2}$ / $\mathrm{FiO}_{2}$ of $252.3 \pm 24.6$. However, all but one of these patients never developed ARDS as defined by this study. These data suggest that surfactant may play a greater role than originally hypothesized in the acute lung injury that occurs in these patients as well as those with ARDS.

In conclusion, at-risk and ARDS patients have significantly altered surfactant phospholipid profiles when compared to normal subjects. Both at-risk and ARDS patients have significantly decreased total phospholipid levels. ARDS patients have significantly decreased levels of phosphatidylcholine and phosphatidylglycerol. At-risk and ARDS patients have significantly decreased surfactant biophysical activity when compared to normal subjects. At-risk and ARDS patients have significantly altered concentrations of the surfactant-associated proteins. At-risk and ARDS patients have significantly decreased surfactant-associated protein, SP-A. ARDS patients have significantly decreased surfactant-associated protein, SP-B.

Based on these findings it is reasonable to suggest that surfactant supplementation may be a useful treatment in ARDS patients. In addition, these findings suggest that surfactant supplementation in patients at-risk to develop ARDS may be useful for the prevention of ARDS, or, that early treatment in the at-risk patient might be beneficial in moderating subsequently developing ARDS. 


\section{Acknowledgments}

The authors would like to acknowledge the excellent technical assistance of Lynn McHugh, R.N., M.N., Kate Leonard, R.N., Darrel Allen, M.S., Patricia Dettenmeier, R.N., and Sally Tricomi.

This study was supported by grants from Ross Laboratories Division of Abbott Laboratories, Columbus, $\mathrm{OH}$.

\section{References}

1. Ashbaugh, D. G., D. B. Bigelow, T. L. Petty, and B. E. Levine. 1967. Acute respiratory distress in adults. Lancet. ii:319-323.

2. Petty, T. L., O. K. Reiss, G. W. Paul, G. W. Silvers, and N. D. Elkins. 1977. Characteristics of pulmonary surfactant in adult respiratory distress syndrome associated with trauma and shock. Am. Rev. Respir. Dis. 115:531-536.

3. Petty, T. L., G. W. Silvers, G. W. Paul, and R. E. Stanford. 1979. Abnormalities in lung elastic properties and surfactant function in adult respiratory distress syndrome. Chest. 75:571-574.

4. Hallman, M., R. Spragg, J. H. Harrell, K. M. Moser, and L. Gluck. 1982. Evidence of lung surfactant abnormality in respiratory failure. Study of bronchoalveolar lavage phospholipids, surface activity, phospholipase activity, and plasma myoinositol. J. Clin. Invest. 70:673-683.

5. Bachofen, M., and E. R. Weibel. 1977. Alterations of the gas exchange apparatus in adult respiratory insufficiency associated with septicemia. Am. Rev. Respir. Dis. 116:589-615.

6. Fatone, J. C., and P. A. Ward. 1982. Role of oxygen derived free radicals and metabolites in leukocyte dependent inflammatory reactions. Am. J. Pathol. 107:397-418.

7. Rinaldo, J. E., and R. M. Rogers. 1982. Adult respiratory-distress syndrome: changing concepts of lung injury and repair. N. Engl. J. Med. 306:900909.

8. Tate, R. M., and J. E. Repine. 1983. Neutrophils and the adult respiratory distress syndrome. Am. Rev. Respir. Dis. 128:552-558.

9. Fuchimukai, T., T. Fujiwara, A. Takahashi, and G. Enhorning. 1987. Artificial pulmonary surfactant inhibited by proteins. J. Appl. Physiol. 62:429-437.

10. Ikegami, M., A. Jobe, H. Jacobs, and R. Lam. 1984. A protein from the airways of premature lambs that inhibits surfactant function. J. Appl. Physiol. 57:1134-1142.

11. Holm, B. A., and R. H. Notter. 1987. Effects of hemoglobin and cell membrane lipids on pulmonary surfactant activity. J. Appl. Physiol. 63:14341442.

12. Said, S. I., M. E. Avery, R. K. Davis, C. M. Banerjee, and M. El-Gohary. 1965. Pulmonary surface activity in induced pulmonary edema. J. Clin. Invest. 44:458-464.

13. Albert, R. K., S. Lakshminarayan, J. Hildebrandt, W. Kirk, and J. Bulter. 1979. Increased surface tension favors pulmonary edema formation in anesthetized dogs' lungs. J. Clin. Invest. 63:1015-1018.

14. Bredenberg, C. E., A. M. Paskanik, and G. F. Nieman. 1983. High surface tension pulmonary edema. J. Surg. Res. 34:515-523.

15. Jefferies, A. L., T. Kawano, S. Mori, and R. Burger. 1988. Effect of increased surface tension and assisted ventilation on ${ }^{99 m}$ Tc-DTPA clearance. $J$. Appl. Physiol. 64:562-568.

16. Bligh, E. G., and W. J. Dyer. 1959. A rapid method of total lipid extraction and purification. Can. J. Biochem. Physiol. 37:911-917.
17. Peterson, G. L. 1983. Determination of total protein. Methods Enzymol. 91:95-119.

18. Dittmer, J. C., and M. A. Wells. 1969. Quantitative and qualitative analysis of lipids and lipid components. Methods Enzymol. XIV:482-530.

19. Fine, J. B., and H. Sprecher. 1982. Unidimensional thin-layer chromatography of phospholipids on boric acid-impregnated plates. J. Lipid Res. 23:660 663.

20. Mason, R. J., J. Nellenbogen, and J. A. Clements. 1976. Isolation of disaturated phosphatidylcholine with osmium tetroxide. J. Lipid Res. 17:281284.

21. Tsai, M. Y., M. Cain, and M. W. Josephson. 1981. Improved thin-layer chromatography of disaturated phosphatidylcholine in amniotic fluid. Clin. Chem. 27:239-242.

22. Ross, G. F., R. H. Notter, J. Meuth, and J. A. Whitsett. 1986. Phospholipid binding and biophysical activity of pulmonary surfactant-associated protein (SAP-35) and its non-collagenous $\mathrm{COOH}$-terminal domain. J. Biol. Chem. 261:14283-14291.

23. Ross, G. F., B. L. Ohning, D. Tannenbaum, and J. A. Whitsett. 1987. Structural relationships of the major glycoproteins from human alveolar proteinosis surfactant. Biochim. Biophys. Acta. 911:294-305.

24. McMahan, M. J., F. Mimouni, M. Miodovnik, W. M. Hull, and J. A. Whitsett. 1987. Surfactant associated protein (SAP-35) in amniotic fluid from diabetic and non-diabetic pregnancies. Obstet. Gynecol. 70:94-98.

25. Whitsett, J. A., W. M. Hull, B. Ohning, G. Ross, and T. E. Weaver. 1986. Immunologic identification of a pulmonary surfactant-associated protein of molecular weight $=6,000$ Daltons. Pediatr. Res. 20:744-749.

26. Heinrikson, R. L., and S. C. Meredith. 1984. Amino acid analysis by reverse-phase high performance liquid chromatography: precolumn derivatization with phenylisothiocyanate. Anal. Biochem. 136:65-74.

27. Bidlingmeyer, B. A., S. A. Cohen, and T. L. Tarvin. 1984. Rapid analysis of amino acids using pre-column derivatization. J. Chromatogr. 336:93-104.

28. Edman, P., and G. Begg. 1967. A protein sequenator. Eur. J. Biochem. $1: 80-91$.

29. Hewick, R. M., M. W. Hunkapiller, L. E. Hood, and W. J. Dreyer. 1981. A gas-liquid solid phase peptide and protein sequenator. J. Biol. Chem. 256:79907997.

30. Olafson, R. W., U. Rink, S. Kielland, S. H. Yu, J. Chung, P. G. Harding, and F. Possmayer. 1987. Protein sequence analysis studies on the low molecular weight hydrophobic proteins associated with bovine pulmonary surfactant. Biochem. Biophys. Res. Commun. 148:1406-1411.

31. Weaver, T. E., V. K. Sarin, N. Sawtell, W. M. Hull, and J. A. Whitsett. 1988. Identification of surfactant proteolipid SP-B in human surfactant and fetal lung. J. Appl. Physiol. 65:982-987.

32. Enhorning, G. 1977. Pulsating bubble technique for evaluating pulmonary surfactant. J. Appl. Physiol. 43:198-203.

33. Hollander, M., and D. A. Wolfe. 1973. Nonparametric Statistical Methods. John Wiley and Sons, Inc., New York. 68-75.

34. Tomashefski, J. F. 1990 . Pulmonary pathology of the adult respiratory distress syndrome. Clin. Chest Med. 11:593-619.

35. Pison, U., W. Seeger, R. Buchhorn, T. Joka, M. Brand, U. Obertacke, H. Neuhof, and K. Schmit-Neuerburg. 1989. Surfactant abnormalities in patients with respiratory failure after multiple trauma. Am. Rev. Respir. Dis. 140:10331039.

36. Pison, U., U. Obertacke, M. Brand, W. Seeger, T. Joka, J. Bruch, and K. P. Schmit-Neuerburg. 1990. Altered pulmonary surfactant in uncomplicated and septicemia-complicated courses of acute respiratory failure. J. Trauma. 30:1926. 